\title{
Income differences in screening, incidence, postoperative complications, and mortality of thyroid cancer in South Korea: a national population-based time trend study
}

Hee-Yeon Kang ${ }^{1}$, Ikhan Kim ${ }^{2,3}$, Yeon-Yong Kim ${ }^{4}$, Jinwook Bahk ${ }^{5}$ and Young-Ho Khang ${ }^{1,2^{*}}$ (1)

\begin{abstract}
Background: The incidence of thyroid cancer (TC) has increased rapidly over the past few decades in Korea. This study investigated whether the TC epidemic has been driven by overdiagnosis.

Methods: We calculated the TC screening rate from mid-2008 through mid-2014, and the incidence, postoperative complication, and mortality rates of TC between 2006 and 2015, using data from the Korea Community Health Survey, the National Health Insurance Database, and the cause-of-death data of Statistics Korea. Trends in agestandardized rates of all indicators were examined, along with income gaps therein. Analyses were conducted for lung cancer and stroke as negative control outcomes.

Results: The incidence rate of TC increased from 46.6 per 100,000 to 115.0 per 100,000 between 2006 and 2012, and then decreased to 63.5 per 100,000 in 2015. Despite these remarkable changes in incidence, mortality did not fluctuate during the same period. High income was associated with high rates of screening, incidence, and postoperative complications, while low income showed an association with a high mortality rate. Analyses using negative control outcomes showed that high income was associated with low rates of both incidence and mortality, which contrasted with the patterns of TC. The recent decreases in TC incidence and postoperative complications, which reflect societal concerns about the overdiagnosis of TC, were more pronounced in highincome individuals than in low-income individuals.
\end{abstract}

Conclusions: The time trends in income gaps in screening, incidence, postoperative complications, and mortality of TC, as well as negative control outcomes, provided corroborating evidence of TC overdiagnosis in Korea.

Keywords: Incidence, Income, Medical overuse, Overdiagnosis, Postoperative complication, Thyroid cancer

\footnotetext{
* Correspondence: yhkhang@snu.ac.kr

${ }^{1}$ Institute of Health Policy and Management, Seoul National University

Medical Research Center, Seoul, Republic of Korea

${ }^{2}$ Department of Health Policy and Management, Seoul National University

College of Medicine, Seoul, Republic of Korea

Full list of author information is available at the end of the article
}

(C) The Author(s). 2020 Open Access This article is licensed under a Creative Commons Attribution 4.0 International License, which permits use, sharing, adaptation, distribution and reproduction in any medium or format, as long as you give appropriate credit to the original author(s) and the source, provide a link to the Creative Commons licence, and indicate if changes were made. The images or other third party material in this article are included in the article's Creative Commons licence, unless indicated otherwise in a credit line to the material. If material is not included in the article's Creative Commons licence and your intended use is not permitted by statutory regulation or exceeds the permitted use, you will need to obtain permission directly from the copyright holder. To view a copy of this licence, visit http://creativecommons.org/licenses/by/4.0/ The Creative Commons Public Domain Dedication waiver (http://creativecommons.org/publicdomain/zero/1.0/) applies to the data made available in this article, unless otherwise stated in a credit line to the data. 


\section{Background}

Thyroid cancer (TC) incidence has increased in many countries around the world over the last few decades [1-3]. Its incidence in South Korea (hereafter 'Korea') has soared to an epidemic level [4-6]. In Korea, the incidence of TC in 2015 was 7 times higher than in 1999, and the incidence peaked in 2012, with a rate 12 times higher than was observed in 1999 [7]. Increases in TC incidence rates with concomitant lack of changes in TC mortality rate have been considered as evidence for TC overdiagnosis [1-4]. Concerns about the overdiagnosis of TC have been raised in Korea. In 2010, the Korean Thyroid Association revised the management guidelines for patients with thyroid nodules and TC, including limitations on the use of fine needle aspiration cytology [8]. In 2014, the problem of the increase in TC incidence received media attention in Korea [9]. Some Korean doctors publicly pointed out the problems associated with screening for TC, arguing that it was urgent for the Korean government and medical community to restrict overdiagnosis and to take preventive measures against this issue [10]. Recently in Korea, the frequency of surgery for TC nosedived [11]. As a consequence, TC dropped from the most commonly diagnosed type of cancer to the third most commonly diagnosed type of cancer in 2015 in Korea [7]. However, a debate continues over the overdiagnosis of TC in Korea [12].

Overdiagnosis may occur more frequently in highincome strata than in low-income strata because individuals with high income are likely to use more medical services than those with low income, and they are more exposed to the risk of overutilization than low-income individuals $[13,14]$. More sensitive tests tend to be carried out in high-income patients in the screening process, and such measures may lead to an earlier diagnosis, thus increasing the possibility of overdiagnosis [14-16]. Thus, discordant patterns between the relationship of income with $\mathrm{TC}$ incidence and the relationship of income with TC mortality could be used as the corroborating evidence for TC overdiagnosis [13].

This study is based on the hypothesis that the rates of screening, incidence, and postoperative complications of TC would be higher in high-income individuals with greater access to medical care, whereas the mortality rate would show a different pattern. In particular, recently, rising concerns about the overdiagnosis of $\mathrm{TC}$ in Korea have led to decreases in both the incidence of TC and surgery for TC [10], and it was hypothesized that high-income individuals would respond more quickly to social concerns. Furthermore, it was assumed that major causes of death-lung cancer (as a representative of cancers) and stroke (as a representative of cardiovascular diseases)-have relatively a low probability of overdiagnosis, and that the incidence and mortality of lung cancer and stroke by income level would therefore show a different pattern from those of TC.

\section{Methods \\ Data}

The study used data from the Korea Community Health Survey (KCHS) conducted in 2010, 2012, and 2014 by the Korea Centers for Disease Control and Prevention, data from the National Health Information Database (NHID) of National Health Insurance Service (NHIS) between 2001 and 2015, and cause-of-death statistics from Statistics Korea between 2006 and 2015. The KCHS is a nationally representative community-based cross-sectional health survey that targeted adults over 19 years of age [17]. The screening rate of TC was drawn from the KCHS items regarding TC screening. The incidence, mortality, and postoperative complication rates of $\mathrm{TC}$, as well as the incidence and mortality rates of the negative control outcomes, were derived from the NHID and cause-of-death data. The NHID covers whole Korean population and includes income-based insurance premiums, demographic variables, information on the date of death, and information on healthcare utilization, thereby making it possible to analyze the incidence of diseases, medical care utilization, and mortality [18]. The study analyzed the mortality rate using individual linkage between the NHID data and cause-of-death data. Individual linkage of the raw data was conducted within the NHIS, and researchers utilized aggregate data without personal identifiers for the analysis.

This study was approved by the National Health Insurance Service of Korea (NHIS-2018-1-191) and the Seoul National University Hospital Institutional Review Board (IRB No. E-1805-047-944). Informed consent was waived by the board.

\section{Definitions of thyroid cancer screening, incidence, and mortality}

TC examinees were defined as those who responded "yes" to an item including "thyroid cancer" among questions regarding all types of cancer screening (including national cancer screening and opportunistic screening) in the most recent 2 years from the KCHS data. All survey participants in $\mathrm{KCHS}$, regardless of their baseline health status, responded to the question. To calculate the incidence rate of TC in each year, the study targeted patients who were first diagnosed with TC (ICD-10 code: C73) as a primary or secondary diagnosis every year between 2006 and 2015. The first day of treatment was considered as the date of diagnosis each year, and the study targeted patients who were admitted for TC once or more in a year or who received outpatient medical services for TC more than twice. However, patients with a history of any type of treatment for $\mathrm{TC}$ in the 5 
years before the date of diagnosis (e.g., any history between January 1, 2001 and December 31, 2005 for an incident case on January 1, 2006) were considered to have a prior history of TC and were therefore excluded from the calculation of the incidence rate for that year. The number of cases and the age-standardized incidence rates between 2006 and 2015 derived from the NHID using the method described above were very close to those based on the Korea Central Cancer Registry (KCCR) (Supplementary Table S1). Since information on income, medical care utilization, and complications cases was not available in the KCCR, we used the NHID for this study. TC Mortality was defined as instances of people over 20 years of age with TC (ICD-10 code: C73) as the cause of death by year between 2006 and 2015 .

\section{Definition of thyroid cancer surgery-specific complications}

TC surgery-specific complications are defined as those specifically due to TC surgery, including hypoparathyroidism/hypocalcemia and vocal cord/fold paralysis [19]. General complications include postoperative fever, local complications (e.g. infection, hemorrhage, and hematoma), cardiopulmonary complications (e.g. pneumonia), and myocardial infarction, which commonly appears within 30 days after surgery [19]. The incidence of postoperative complications was calculated using patients with TC surgery-specific complications. Diagnostic and surgical procedure codes were confirmed in the healthcare utilization database of the NHID; thus, for this study, patients aged 20 or over who first underwent surgery for TC between 2006 and 2015 were included. Among those patients, postoperative complications were considered to have occurred in individuals who were hospitalized more than once or who used outpatient medical services once or more due to hypoparathyroidism (ICD-10 code: E20.9, E89.2) or vocal cord/fold paralysis (ICD-10 code: J38.0) within 31 to 365 days from the TC surgery date. However, the postoperative complication rate did not include those who used medical services due to the aforementioned complications within only 30 days after surgery, because such instances of complications were considered to have been transient symptoms in accordance with previous studies [19]. Additionally, the postoperative complication rate did not include those who had undergone any treatment for the aforementioned complications during 5 years before surgery, because such patients were considered to have a past medical history. The annual rates of TC surgery by income were also calculated. Thyroid cancer surgery included radical operations on malignant thyroid tumors, total thyroidectomy, and subtotal thyroidectomy, as well as the excision of cervical lymph nodes and neck lymphatic dissections that were performed as part of combined-modality treatment due to cervical lymph node metastasis.

\section{Negative control outcomes}

The negative control outcomes were lung cancer and stroke since they were assumed to be less susceptible to overdiagnosis. The incidence and mortality of both lung cancer and stroke were defined similarly to those of TC. In the annual healthcare utilization database of NHID, incident cases of lung cancer were defined as individuals 20 years old or over who were first diagnosed with lung cancer (ICD-10 code: C33-C34) between 2006 and 2015. This study targeted patients who were hospitalized for lung cancer at least once or had outpatient visits twice or more for a year from the diagnosis date, as for cases of thyroid cancer. Then, patients with a past history those who have been treated for lung cancer during the five years before the diagnosis date - were excluded. The number of cases and the age-standardized incidence rates of lung cancer from the NHID were also very close to those based on the KCCR (Supplementary Table S2). Using the annual healthcare utilization database between 2006 and 2015, incident cases of stroke were defined by identifying patients 30 years of age or over who had received their first diagnosis of stroke (ICD-10 code: I60-I64) in that year and including those were hospitalized with stroke more than once in each year. In addition, patients who had admitted for stroke the prior 5 years in each year between 2006 and 2015 were excluded because they were considered to have a past medical history. As with mortality from thyroid cancer, cases of mortality from lung cancer and stroke were defined based on linkage between the cause-of-death data from Statistics Korea and the NHID data. Those 20 years of age or older with an ICD-10 cause-of-death code of C33-C34 and those 30 years of age or older with an ICD-10 cause-of-death code of I60-I64 were defined as cases of mortality from lung cancer and stroke, respectively.

\section{Income}

Household income from the KCHS data and national health insurance (NHI) premiums from the NHID data were used as an income index. Many previous studies in Korea have used the NHI premiums as an indicator of income [20,21]. For the income index of TC examinees in the KCHS data, this study utilized converted values of equivalized income, in which items related to annual or monthly household income were adjusted for household size. The income index of the incidence, mortality, and postoperative complications of $\mathrm{TC}$ and the negative control outcomes was calculated using equivalized income adjusted for household size using NHI premium data from the NHID. In addition, each equivalized 
income parameter drawn from the KCHS or NHID was divided into income quintiles by year, sex, and 5year age group [22].

\section{Statistical analysis}

The changing patterns of the age-standardized screening, incidence, surgery, postoperative complication, and mortality rates of TC were analyzed by sex and income level between 2006 and 2015. For age standardization, subjects were divided into 5-year groups, and the 2010 mid-year population from Statistics Korea was used as the reference. Unlike other types of cancer, TC has a very low mortality rate; thus, the annual age- standardized mortality rate by income quintile was derived by combining the data between 2006 and 2010 and the data between 2011 and 2015, respectively, to ensure the stability of TC mortality rates. The incidence and mortality rates of lung cancer and stroke (the negative control outcomes) were derived using age-standardized rates for each income quintile by calendar year between 2006 and 2015. All analyses were performed using SAS version 9.4 (SAS Institute Inc., Cary, NC, USA).

\section{Results}

Table 1 presents the numbers of study subjects aged 20 or over from the database that was used to derive the

Table 1 Study subjects (aged 20 or over) from KCHS and NHID in Korea, 2006-2015

\begin{tabular}{|c|c|c|c|c|c|c|c|}
\hline \multirow[t]{2}{*}{ Sex } & \multirow[t]{2}{*}{ Year } & \multicolumn{2}{|l|}{ KCHS } & \multicolumn{4}{|l|}{ NHID } \\
\hline & & $\begin{array}{l}\text { No. of study } \\
\text { subjects }\end{array}$ & $\begin{array}{l}\text { No. of subjects } \\
\text { with TC screening }\end{array}$ & $\begin{array}{l}\text { No. of total } \\
\text { population }\end{array}$ & $\begin{array}{l}\text { No. of TC } \\
\text { incident cases }\end{array}$ & $\begin{array}{l}\text { No. of subjects with } \\
\text { postoperative complications }\end{array}$ & $\begin{array}{l}\text { No. of TC } \\
\text { deaths }\end{array}$ \\
\hline \multirow[t]{10}{*}{ All } & 2006 & - & - & $35,500,836$ & 15,943 & 3043 & 322 \\
\hline & 2007 & - & - & $35,881,719$ & 20,564 & 3565 & 358 \\
\hline & 2008 & - & - & $36,504,109$ & 26,474 & 4450 & 332 \\
\hline & 2009 & - & - & $36,925,146$ & 32,480 & 5654 & 342 \\
\hline & 2010 & 225,116 & 31,701 & $36,669,946$ & 34,981 & 6946 & 344 \\
\hline & 2011 & - & - & $37,725,424$ & 40,081 & 5640 & 382 \\
\hline & 2012 & 225,188 & 42,249 & $38,139,862$ & 44,174 & 6937 & 358 \\
\hline & 2013 & - & - & $38,574,788$ & 42,818 & 7694 & 379 \\
\hline & 2014 & 224,994 & 44,942 & $38,941,467$ & 31,923 & 6610 & 339 \\
\hline & 2015 & - & - & $39,696,326$ & 25,165 & 4294 & 331 \\
\hline \multirow[t]{10}{*}{ Women } & 2006 & - & - & $18,007,925$ & 13,629 & 2631 & 234 \\
\hline & 2007 & - & - & $18,180,997$ & 17,464 & 3111 & 253 \\
\hline & 2008 & - & - & $18,507,966$ & 22,294 & 3851 & 230 \\
\hline & 2009 & - & - & $18,717,880$ & 27,307 & 4924 & 233 \\
\hline & 2010 & 122,432 & 20,011 & $18,589,856$ & 28,956 & 5889 & 254 \\
\hline & 2011 & - & - & $19,114,446$ & 33,125 & 4754 & 269 \\
\hline & 2012 & 123,971 & 27,322 & $19,326,295$ & 36,161 & 5860 & 235 \\
\hline & 2013 & - & - & $19,541,003$ & 34,362 & 6269 & 266 \\
\hline & 2014 & 123,226 & 29,248 & $19,717,940$ & 25,529 & 5431 & 256 \\
\hline & 2015 & - & - & $20,095,936$ & 19,768 & 3449 & 228 \\
\hline \multirow[t]{10}{*}{ Men } & 2006 & - & - & $17,492,911$ & 2314 & 412 & 88 \\
\hline & 2007 & - & - & $17,700,722$ & 3100 & 454 & 105 \\
\hline & 2008 & - & - & $17,996,143$ & 4180 & 599 & 102 \\
\hline & 2009 & - & - & $18,207,266$ & 5173 & 730 & 109 \\
\hline & 2010 & 102,684 & 11,690 & $18,080,090$ & 6025 & 1057 & 90 \\
\hline & 2011 & - & - & $18,610,978$ & 6956 & 886 & 113 \\
\hline & 2012 & 101,217 & 14,927 & $18,813,567$ & 8013 & 1077 & 123 \\
\hline & 2013 & - & - & $19,033,785$ & 8456 & 1425 & 113 \\
\hline & 2014 & 101,768 & 15,694 & $19,223,527$ & 6394 & 1179 & 83 \\
\hline & 2015 & - & - & $19,600,390$ & 5397 & 845 & 103 \\
\hline
\end{tabular}


screening, incidence, postoperative complication, and mortality rates of TC. The number of study subjects in the KCHS data was relatively similar over the years: 225 , 116 in 2010, 225,188 in 2012, and 224,994 in 2014. The respondents who had received TC screening in the most recent 2 years gradually increased. The number of study subjects in the NHID between 2006 and 2015 has consistently increased, from 35,500,836 in 2006 to 39,696, 326 in 2015. From 2006 to 2015, the number of patients with incident TC increased from 15,943 in 2006 to 44, 174 in 2012, but then decreased to 25,165 in 2015. The number of patients with postoperative complications of TC surgery increased continually between 2006 and 2010, decreased in 2011, and then increased to its peak of 7694 in 2013. Later, the number of patients gradually decreased, along with $\mathrm{TC}$ incidence. In contrast to the incidence and postoperative complication rate of $\mathrm{TC}$, the mortality of TC remained between 300 and 400 every year, without any significant fluctuations between 2006 and 2015. The magnitudes of the screening, incident, postoperative complications, and deaths cases of TC were much higher for women than men. However, the trends were similar to both women and men. The numbers of patients with the negative control outcomes by year are presented in Supplementary Table S3.

Figure 1 presents the age-standardized incidence and mortality rates of TC in Korea between 2006 and 2015. TC incidence in men and women combined soared from 46.6 to 115.0 per 100,000 from 2006 to 2012 , but then plummeted through 2015. TC incidence among women in 2012 was 188.2 per 100,000 , reflecting a nearly 2.4 fold increase from 79.1 in 2006. The incidence of TC in men was much lower than in women, but it increased by 3.2 times, from 13.9 per 100,000 in 2006 to 44.0 in 2013. The increasing trend in TC incidence nosedived starting in 2012 among women and starting in 2013 among men. However, the mortality rate remained very low, at approximately 1.0 per 100,000 regardless of sex, and it showed no significant fluctuations between 2006 and 2015 (Supplementary Tables S4 and S5).

Table 2 presents the age-standardized screening, incidence, postoperative complication, and mortality rates of TC by calendar year and income level. In 2010, 2012, and 2014, from $12,562.0$ to $18,717.5$ adults aged 20 or over per 100,000 had undergone TC screening in the most recent 2 years. Between 2006 and 2015, TC incidence ranged from 46.6 to 115.0 per 100,000 , and the postoperative complication rate was 8.9 to 19.7 per 100 , 000. This indicates that postoperative complications occurred in 14.1 to $20.5 \%$ of incident TC cases every year. In contrast, the mortality of $\mathrm{TC}$ was stable over time, ranging only from 1.0 per 100,000 between 2006 and 2010 and 0.8 per 100,000 between 2011 and 2015. Every year between 2006 and 2015, the highest income quintile showed high screening and incidence rates of TC. The highest income quintile also showed high rates of postoperative complications associated with $\mathrm{TC}$ in most years. However, the mortality rate showed an opposite pattern, as the highest mortality rate occurred in the lowest income quintile.

As shown in Fig. 2, every indicator, except the mortality rate, showed a higher age-standardized rate as income increased (Fig. 2a, b, and c). However, the mortality rate showed the opposite trend (Fig. 2d). The mortality rate of the lowest income quintile was higher than that of the other income quintiles. Furthermore, postoperative complications of TC showed a positive association with income between 2006 and 2013. In 2011, the complication rate decreased in every income group, and then it increased in 2012. The incidence rate began to decline in 2013. The highest income quintile complication rate nosedived, indicating that the highest income participants responded more quickly to the decrease in TC incidence than other income quintiles (Fig. 2c). The annual rates of TC surgery according to income quintiles (Supplementary Figure S1) were also similar to the patterns in TC incidence. On average, about $93 \%$ of total incidence cases undergone TC surgery (Supplementary Table S6). The ratios of postoperative complication rates to TC surgery rates were slightly greater in low-income quintiles than high-income quintiles.

Figure 3 presents the age-standardized incidence and mortality rates of lung cancer and stroke by year and income level. Both lung cancer and stroke showed different patterns of incidence and mortality rates from TC. The incidence and mortality rates of lung cancer and stroke continually decreased. During the observation period, TC showed a rapid increase and decrease, but no similar fluctuation was observed for lung cancer (Fig. 3a) and stroke (Fig. 3b). The incidence of lung cancer showed no clear pattern by calendar year, although the lung cancer mortality rate decreased (Fig. 3a). The incidence and mortality rates of stroke showed a consistent decrease between 2006 and 2015 (Fig. 3b). Every income group also presented a similar pattern. Furthermore, the patterns in incidence rates by income quintiles showed an opposite pattern from that of TC. Whereas TC had a high incidence and low mortality rate in the highest income quintile, for lung cancer and stroke, the lowest income quintile showed the highest rates of incidence and mortality (Fig. 3c, d, e, and f).

\section{Discussion}

The study presented nationally representative rates of TC screening, incidence, postoperative complication, and mortality in Korea. In 2012, the year with the highest incidence of TC, the rate of TC screening within the most recent 2 years was $17,449.9$ per 100,000 adults aged 


\section{a}

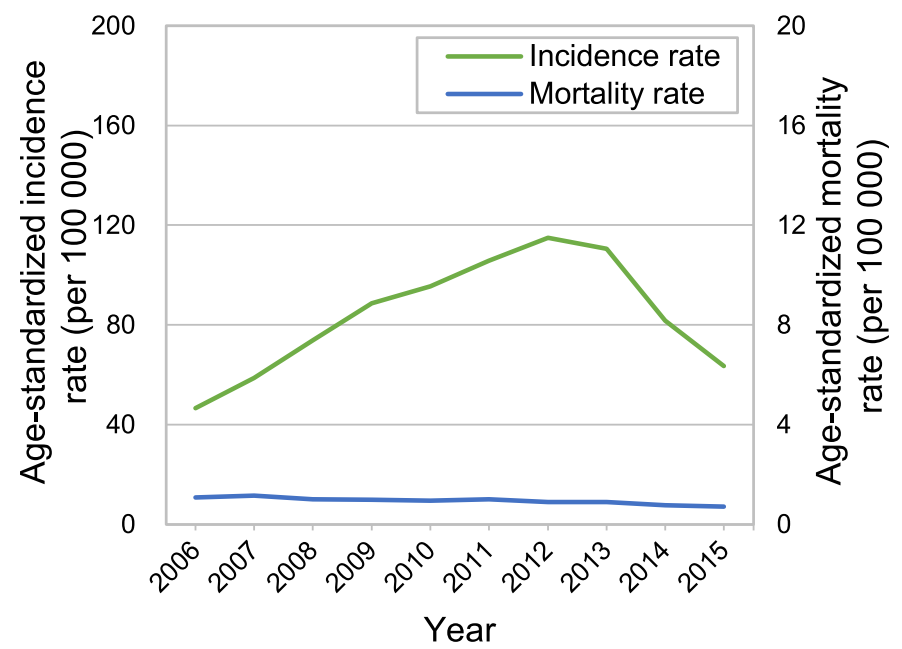

\section{b}

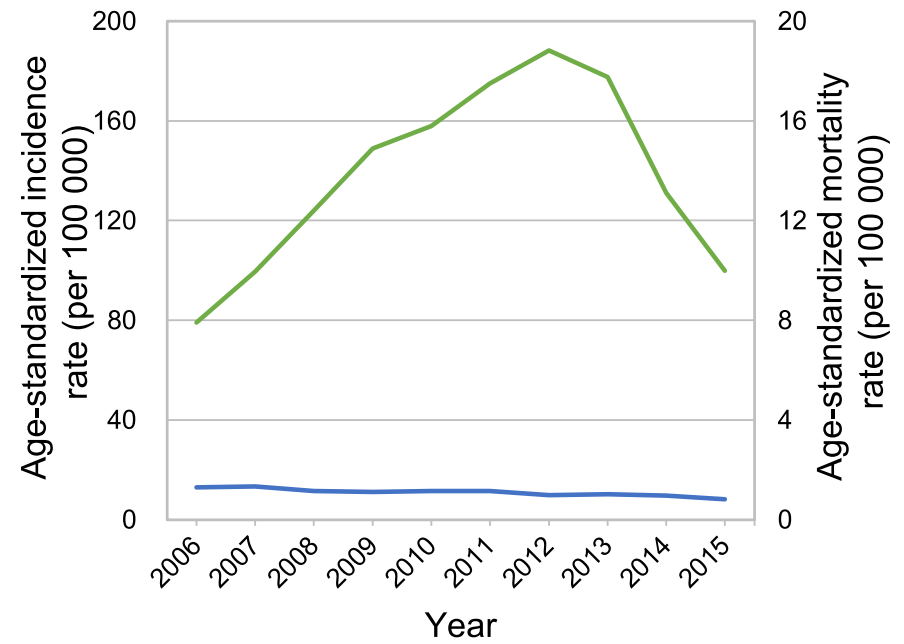

C

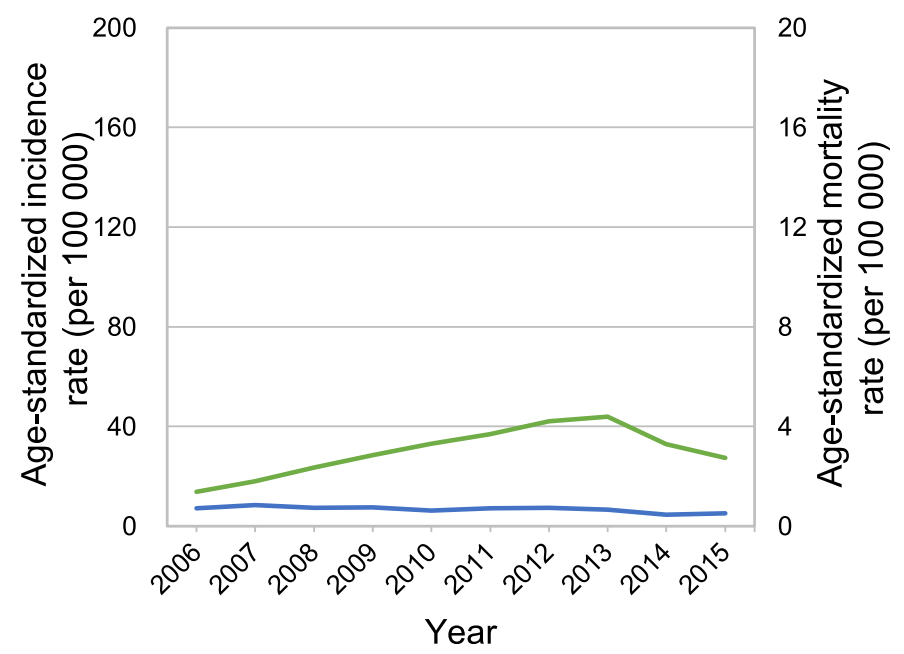

Fig. 1 Trends in age-standardized incidence and mortality rates of thyroid cancer in Korea, 2006-2015. a women and men combined. b women. c men 


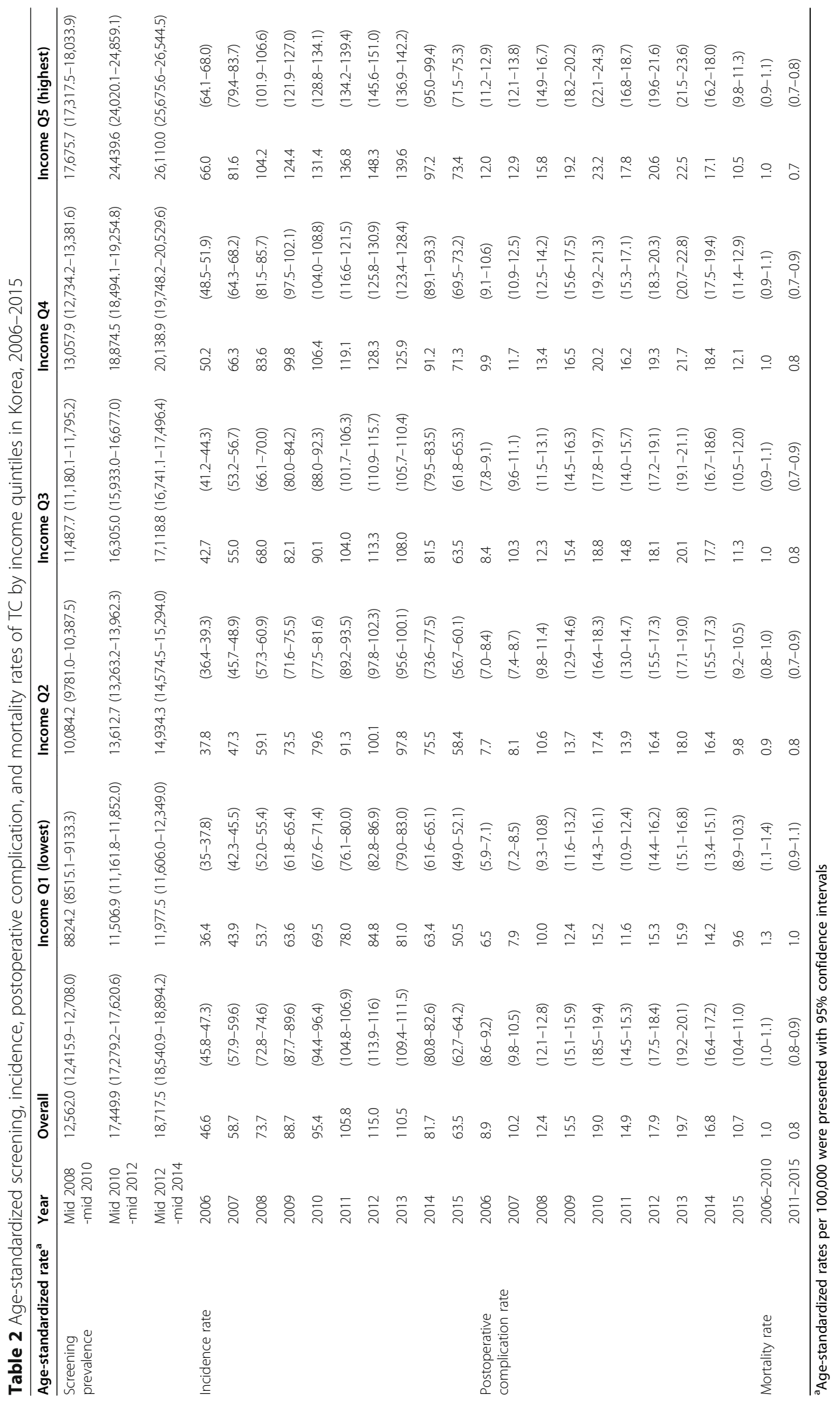



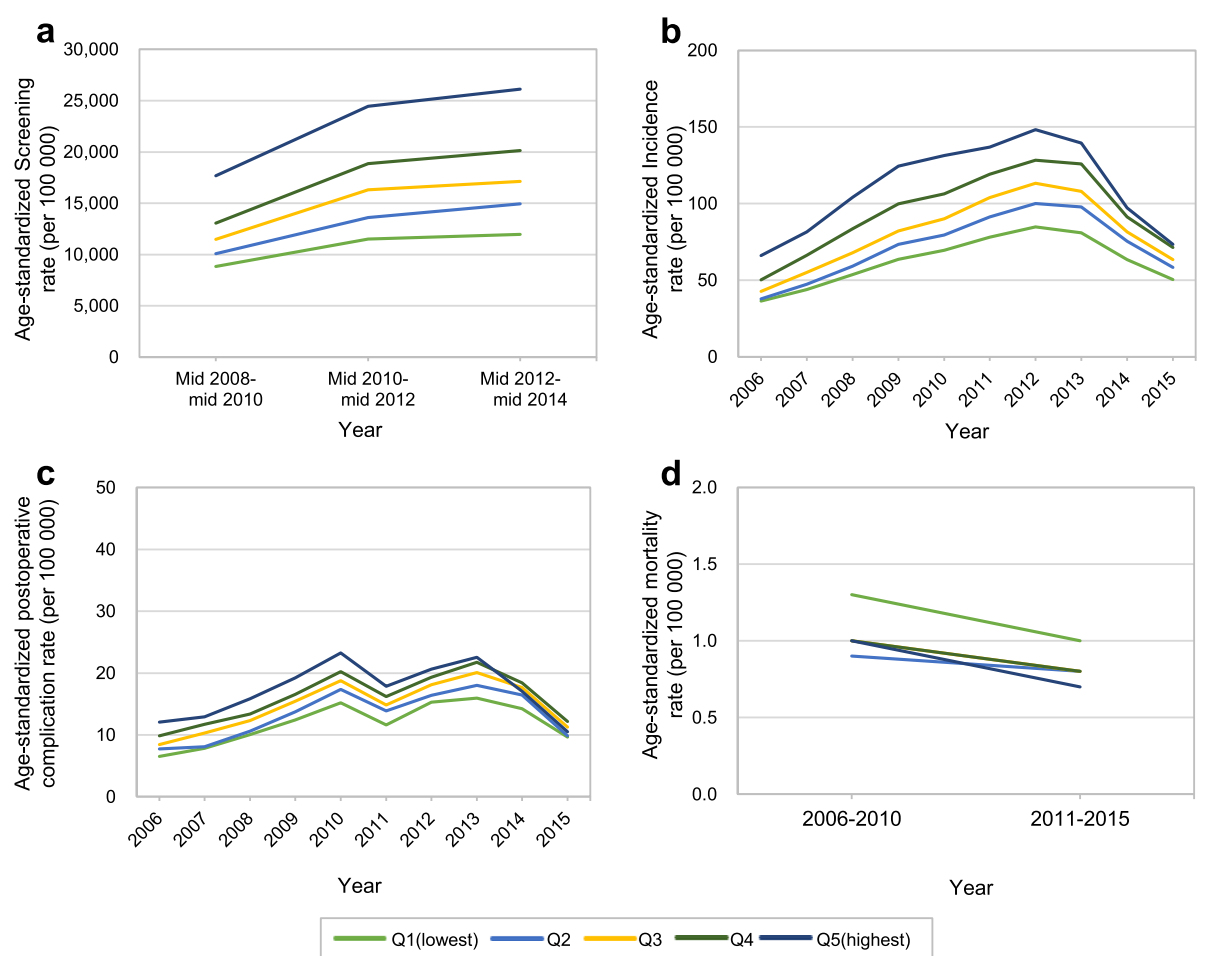

Fig. 2 Income differences in screening, incidence, postoperative complications, and mortality of thyroid cancer in South Korea, 2006-2015. a screening rate. $\mathbf{b}$ incidence rate. $\mathbf{c}$ postoperative complication rate. $\mathbf{d}$ mortality rate

20 or over, while the incidence of TC was 115 per 100,000 . In the same year, 17.9 per 100,000 had postoperative complications of TC and 0.9 per 100,000 died of TC. Incident cases of TC potentially included those who had not undergone TC screening, so these results show that TC screening led to a diagnosis of TC in fewer than 1 of 100 examinees. Furthermore, the complication rate in 2012 was $15.6 \%$ of incident TC cases $\left(17.9 / 115^{*} 100\right)$. Thus, the complication rate was approximately 20 times higher than the mortality rate. It should be noted that this study only examined the rate of TC surgery-specific complications (hypoparathyroidism and vocal cord/fold paralysis) and excluded transient complications within 30 days after surgery. Active surgical interventions for TC are likely to decrease the mortality rate of $\mathrm{TC}$, but this benefit should be balanced with the harm to the population by the postoperative complications of TC surgery. In most cases, the postoperative complications of $\mathrm{TC}$ surgery are temporary. However, permanent complications could lead to a low quality of life. Permanent vocal cord paralysis could change an individual's voice, and patients with permanent hypoparathyroidism need to receive calcium and vitamin $\mathrm{D}$ for their entire lifetime. In particular, TC surgery performed to vulnerable, high-risk patients, such as elderly patients with comorbidities, could lead to fairly negative results, including low quality of life, pneumonia, infection, heart complications, and death [13, 23]. The findings of this study, therefore, shed light on the magnitude of the side effects of TC surgery.

The incidence of TC showed very significant fluctuations, but the mortality rate showed no notable change. The incidence of TC between 2011 and 2013 increased more than 2-fold from 2006 in all income brackets. This increased incidence in such a short period is difficult to be explained by dietary and environmental risk factors. The increasing trend of TC incidence was more significant in women than in men (Fig. 1), since ultrasonography for breast cancer screening is often performed jointly with thyroid ultrasonography in Korea. The increase in the incidence of TC and the concomitant lack of change in the mortality rate have been regarded as evidence of the overdiagnosis of TC $[4,24,25]$. In the study, the interpretation of the increase in the incidence of $\mathrm{TC}$ as being due to overdiagnosis was further corroborated by data showing that the incidence of TC decreased after 2012, but the mortality rate still showed no changes.

The screening, incidence, surgery rates, and postoperative complication rates of TC were higher in the highincome group than in other income groups. Thyroid cancer screening is conducted as opportunistic health screening and thus might be affected by service users' 


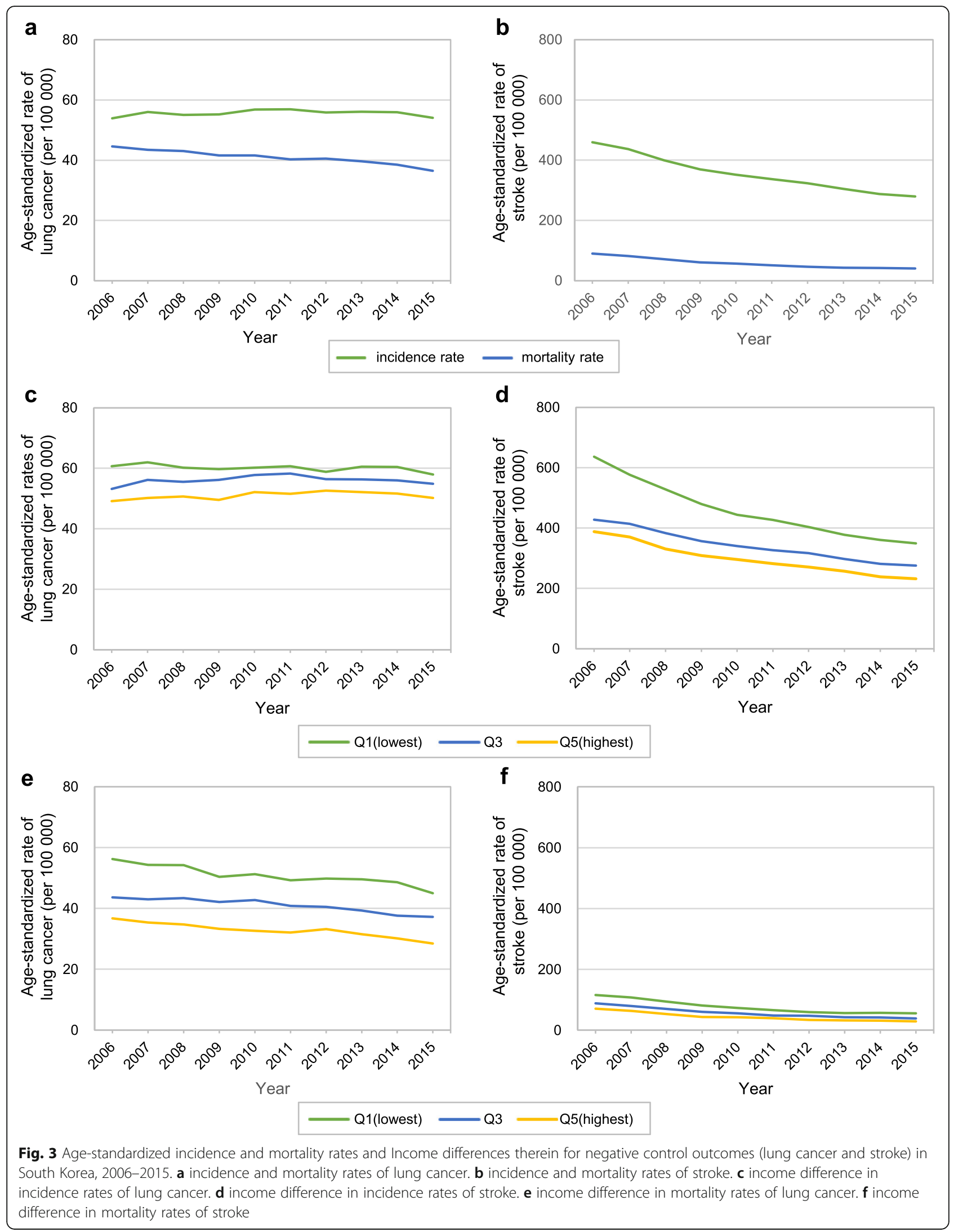


financial capability. Greater use of thyroid cancer screening might produce greater incidence rates, surgery rates, and subsequent postoperative complication rates among high-income strata than among low-income strata. However, a higher mortality rate of $\mathrm{TC}$ was shown in the lowest income bracket. According to a previous review study, no clear relationship has been shown between the mortality rate of TC and socioeconomic status [26]. The high mortality rate in the lowest income group might be because this income group included Medical Aid recipients with underlying health problems [20, 21]. Previous studies in Korea have reported greater in-hospital mortality rates among Medical Aid recipients [27]. Low quality of care and delayed use of proper health care services might have produce greater TC mortality rates especially among the lowest income group in Korea.

The incidence of TC decreased after 2012 as a result of concerns about TC overdiagnosis; in particular, the incidence decreased rapidly in the high-income group. Even the postoperative complication rate nosedived in the highest income group. In 2015, the incidence of TC postoperative complications in the highest income quintile had decreased to the level of the lowest income quintile. This could be interpreted as indicating that high-income individuals responded more rapidly to concerns about the postoperative complications of TC. In 2011, the number of postoperative complications of TC decreased due to the 2010 revision of the management guidelines on thyroid nodules and $\mathrm{TC}$ by the Korean Thyroid Association [8]. Active surveillance associated with this 2010 revision might have contributed to the decline in postoperative complications of TC [28].

Lung cancer and stroke were used as negative control outcomes because these two diseases had a low probability of overdiagnosis. Lung cancer was not included as a component of the cancer screening program in Korea during the study period. No screening program for stroke existed. If the relationships of income with incidence and mortality for these two diseases were similar to the relationships of income with TC incidence and TC mortality, the findings for thyroid cancer are less likely due to overdiagnosis. However, the findings for these two negative control outcomes showed that the incidence and mortality of lung cancer and stroke by income level were different from those of TC, which could corroborate our assertion that the relationship of income with $\mathrm{TC}$ incidence and mortality would be due to overdiagnosis. Lung cancer and stroke showed high incidence and mortality rates in low-income individuals. The high incidence and mortality rates of these diseases in lowincome individuals could be explained through socioeconomic inequalities in risk factors, including gaps in the smoking rate across income levels [29] and similar gaps in blood pressure [30], as well as inequalities in the use of medical services and the quality thereof.

The study has strengths and limitations. This study employed large nationally representative data in Korea containing information on screening, healthcare utilization, and mortality. Several studies have been conducted on the incidence and mortality rates of $\mathrm{TC}$, but very few studies have assessed the screening and complication rates. To the best of our knowledge, no study has investigated gaps across income levels in relation to the aforementioned indicators. Analyses by pathological subtype of $\mathrm{TC}$ were not conducted in this study because we employed NHID to use variables on income and postoperative complications rather than KCCR database. At the time of this study, individual data linkage between NHID and KCCR was not possible. According to a medical records review of TC patients between 1962 and 2009 in Korea, the proportion of small tumors less than $1 \mathrm{~cm}$ in the total cases of TC increased from 6.1 to $43.1 \%$ [31]. In particular, papillary $\mathrm{TC}$, for which overdiagnosis often occurs, accounted for over $90 \%$ of all cases of TC [4, 32]. For example, $97.2 \%$ of total TC were papillary thyroid cancer while only $1.8 \%$ of total TC were follicular cancer in 2008 [33]. A prior Korean study also showed that the increase in TC from 1999 to 2008 was mainly attributed to the increased incidence of small tumors [33]. In addition, a recent study demonstrated that the TC screening rate was highly associated with the papillary $\mathrm{TC}$ incidence rate between 2008 and 2010 across 16 administrative regions of Korea [34]. Even if papillary TC were concentrated in a particular income group, the results on the incidence of TC by income level found in this study would hardly change.

\section{Conclusions}

This study suggests that the considerable fluctuations in the TC incidence over the past decade in Korea were driven by overdiagnosis. The study showed a high screening rate of TC in high-income individuals, leading to high incidence and postoperative complication rates of TC in that group. However, a similar pattern was not shown for the mortality rate. The incidence of lung cancer and stroke, negative control outcomes, did not show a similar pattern to TC by income level. In particular, the recent rapid decrease in the incidence and complication rates in high-income individuals is likely to have been a result of societal concerns over the TC overdiagnosis in Korea. These results provide corroborating evidence that overdiagnosis has caused a considerable proportion of the increase in TC incidence in Korea. 


\section{Supplementary Information}

The online version contains supplementary material available at https://doi. org/10.1186/s12885-020-07597-4

Additional file 1: Table S1. Annual comparison of numbers of incident cases, crude incidence rate, and age-standardized incidence rate of thyroid cancer between the National Health Information Database (NHID) from the National Health Insurance Service and the Korea Central Cancer Registry (KCCR). Table S2. Annual comparison of numbers of incident cases, crude incidence, and age-standardized incidence rate of lung cancer between the National Health Information Database (NHID) from the National Health Insurance Service and the Korea Central Cancer Registry (KCCR). Table S3. Study subjects of patients with the negative control outcomes from the National Health Information Database (NHID) in Korea, 2006-2015. Table S4. Age-standardized screening prevalence, incidence rate, postoperative complication rate, and mortality rate of thyroid cancer according to income quintiles in women, Korea, 2006-2015. Table S5. Age-standardized screening prevalence, incidence rate, postoperative complication rate, and mortality rate of thyroid cancer according to income quintiles in men, Korea, 2006-2015. Table S6. Ratios of thyroid cancer surgery to thyroid cancer incidence according to income quintiles and ratios of postoperative complications to thyroid cancer surgery according to income quintiles, Korea, 2006-2015

Additional file 2: Figure S1. Income differences in age-standardized surgery rate of thyroid cancer in Korea. (PPTX $79 \mathrm{~kb}$ )

\section{Abbreviations}

TC: Thyroid cancer; KCHS: Korea Community Health Survey; NHID: National Health Information Database; NHIS: National Health Insurance Service; KCCR: Korea Central Cancer Registry; NHI: National Health Insurance (NHI)

\section{Acknowledgements}

Not applicable.

\section{Authors' contributions}

YHK conceptualized the study, supervised the data analysis. HYK, IK, YYK contributed to data curation. HYK and IK analyzed and interpreted data. JB designed the analytic strategy. YHK and HYK drafted the manuscript. All authors read and approved the final manuscript.

\section{Funding}

This study was supported by the Mid-career Researcher Program of the National Research Foundation (NRF) funded by the Ministry of Science \& ICT (No. NRF-2014R1A2A1A11051392 and No. NRF-2017R1A2A2A05069746) and a grant of the Korea Health Technology R\&D Project through the Korea Health Industry Development Institute (KHIDI), funded by the Ministry of Health \& Welfare, Republic of Korea [grant number: HI18C0446].

\section{Availability of data and materials}

The Korea Community Health Survey (KCHS) data are publicly available. The National Health Information Database (NHID) that support the finding of this study are available from the Big Data Steering Department of the National Health Insurance Service, but restrictions apply to the availability of these data, which were used under license for the current study, and so are not publicly available. The authors used the aggregate population and death data without personal identification numbers. De-identified aggregate data are available from the corresponding author after permissions are obtained from the Big Data Steering Department of the National Health Insurance Service in Korea.

\section{Ethics approval and consent to participate}

This study was approved by the Seoul National University Hospital Institutional Review Board (IRB No. E-1805-047-944). Informed consent was waived by the board.

\section{Consent for publication}

Not applicable.

\section{Competing interests}

The authors declare that they have no competing interests.

\section{Author details}

${ }^{1}$ Institute of Health Policy and Management, Seoul National University Medical Research Center, Seoul, Republic of Korea. ${ }^{2}$ Department of Health Policy and Management, Seoul National University College of Medicine, Seoul, Republic of Korea. ${ }^{3}$ Department of Health Policy and Management, Jeju National University School of Medicine, Jeju, Republic of Korea. ${ }^{4}$ Big Data Steering Department, National Health Insurance Service, Wonju, Republic of Korea. ${ }^{5}$ Department of Public Health, Keimyung University, Daegu, Republic of Korea.

Received: 17 March 2020 Accepted: 30 October 2020 Published online: 11 November 2020

\section{References}

1. Vaccarella S, Franceschi S, Bray F, Wild CP, Plummer M, Dal ML. Worldwide thyroid-Cancer epidemic? The increasing impact of Overdiagnosis. N Engl J Med. 2016;375(7):614-7.

2. La Vecchia C, Malvezzi M, Bosetti C, Garavello W, Bertuccio P, Levi F, et al. Thyroid cancer mortality and incidence: a global overview. Int J Cancer. 2015;136(9):2187-95.

3. Lortet-Tieulent J, Franceschi S, Dal Maso L, Vaccarella S. Thyroid cancer "epidemic" also occurs in low- and middle-income countries. Int J Cancer. 2019;144(9):2082-7.

4. Ahn HS, Kim HJ, Welch HG. Korea's thyroid-Cancer "epidemic" -- screening and Overdiagnosis. N Engl J Med. 2014;371(19):1765-7.

5. Vaccarella S, Dal Maso L, Laversanne M, Bray F, Plummer M, Franceschi S. The impact of diagnostic changes on the rise in thyroid Cancer incidence: a population-based study in selected high-resource countries. Thyroid. 2015; 25(10):1127-36.

6. Brito JP, Davies L. Is there really an increased incidence of thyroid cancer? Curr Opin Endocrinol Diabetes Obes. 2014;21(5):405-8.

7. Cancer registration statistics: cancer incident cases and incidence rates by site (24 items) and sex. KOrean Statistical Information Service (KOSIS), Statistics Korea. 2018. http://kosis.kr/statHtml/statHtml.do?orgld=117\&tblld= DT_117N_A00022\&conn_path=12. Accessed 31 Jan, 2018.

8. Yi KH, Park YJ, Koong SS, Kim JH, Na DG, Ryu JS, et al. Revised Korean thyroid association management guidelines for patients with thyroid nodules and thyroid Cancer. Endocrinol Metab. 2010;25(4):270-97.

9. Jung $\mathrm{MH}$, Jung SE. What caused jump in thyroid cancer cases? The Korea Times. 2014 March 27, 2014. http://www.koreatimes.co.kr/www/news/ culture/2014/03/319_154183.html. Accessed 19 Jan, 2019.

10. Lee $\mathrm{JH}$, Shin SW. Overdiagnosis and screening for thyroid cancer in Korea. Lancet. 2014;384(9957):1848.

11. Ahn HS, Welch HG. South Korea's thyroid-Cancer "epidemic"--turning the tide. N Engl J Med. 2015;373(24):2389-90.

12. Jeon MJ, Kim HK, Kim EH, Kim ES, Yi HS, Kim TY, et al. Decreasing diseasespecific mortality of differentiated thyroid Cancer in Korea: a multicenter cohort study. Thyroid. 2018;28(9):1121-7.

13. Welch HG, Fisher ES. Income and Cancer Overdiagnosis - when too much care is harmful. N Engl J Med. 2017;376(23):2208-9.

14. Zagzag J, Kenigsberg A, Patel KN, Heller KS, Ogilvie JB. Thyroid cancer is more likely to be detected incidentally on imaging in private hospital patients. J Surg Res. 2017;215:239-44.

15. Brodersen J. How to conduct research on overdiagnosis. A keynote paper from the EGPRN may 2016, Tel Aviv. Eur J Gen Pract. 2017;23(1):78-82.

16. Welch HG, Schwartz L, Woloshin S. Overdiagnosed : making people sick in the pursuit of health. Boston, Massachusetts: Beacon Press; 2011.

17. Kang YW, Ko YS, Kim YJ, Sung KM, Kim HJ, Choi HY, et al. Korea community health survey data profiles. Osong Public Health Res Perspect. 2015;6(3): 211-7.

18. Cheol Seong S, Kim YY, Khang YH, Heon Park J, Kang HJ, Lee H, et al. Data resource profile: the National Health Information Database of the National Health Insurance Service in South Korea. Int J Epidemiol. 2017;46(3):799-800.

19. Papaleontiou M, Hughes DT, Guo C, Banerjee M, Haymart MR. Populationbased assessment of complications following surgery for thyroid Cancer. J Clin Endocrinol Metab. 2017;102(7):2543-51.

20. Khang YH, Yang S, Cho HJ, Jung-Choi K, Yun SC. Decomposition of socioeconomic differences in life expectancy at birth by age and cause of death among 4 million south Korean public servants and their dependents. Int J Epidemiol. 2010;39(6):1656-66. 
21. Khang YH, Bahk J, Yi N, Yun SC. Age- and cause-specific contributions to income difference in life expectancy at birth: findings from nationally representative data on one million south Koreans. Eur J Pub Health. 2016; 26(2):242-8.

22. Kim I, Bahk J, Kim YY, Lee J, Kang HY, Lee J, et al. Comparison of districtlevel smoking prevalence and their income gaps from two National Databases: the National Health Screening Database and the community health survey in Korea, 2009-2014. J Korean Med Sci. 2018;33(6):e44.

23. Grogan RH, Mitmaker EJ, Hwang J, Gosnell JE, Duh QY, Clark OH, et al. A population-based prospective cohort study of complications after thyroidectomy in the elderly. J Clin Endocrinol Metab. 2012;97(5):1645-53.

24. Davies L, Welch HG. Current thyroid cancer trends in the United States. JAMA Otolaryngol Head Neck Surg. 2014;140(4):317-22.

25. Davies L, Morris LG, Haymart M, Chen AY, Goldenberg D, Morris J, et al. American Association of Clinical Endocrinologists and American College of endocrinology disease state clinical review: the increasing incidence of thyroid Cancer. Endocr Pract. 2015;21 (6):686-96.

26. Faggiano F, Partanen T, Kogevinas M, Boffetta P. Socioeconomic differences in cancer incidence and mortality. IARC Sci Publ. 1997;138:65-176.

27. Kim Y, Oh J, Jha A. Contribution of hospital mortality variations to socioeconomic disparities in in-hospital mortality. BMJ Qual Saf. 2014;23(9): $741-8$.

28. Haymart MR, Miller DC, Hawley ST. Active surveillance for low-risk cancers a viable solution to overtreatment? N Engl J Med. 2017;377(3):203-6.

29. Kim I, Bahk J, Yoon TH, Yun SC, Khang YH. Income differences in smoking Prevalences in 245 districts of South Korea: patterns by area deprivation and urbanity, 2008-2014. J Prev Med Public Health. 2017;50(2):100-26.

30. Khang YH, Lynch JW, Jung-Choi K, Cho HJ. Explaining age-specific inequalities in mortality from all causes, cardiovascular disease and ischaemic heart disease among south Korean male public servants: relative and absolute perspectives. Heart. 2008;94(1):75-82.

31. Cho BY, Choi HS, Park YJ, Lim JA, Ahn HY, Lee EK, et al. Changes in the clinicopathological characteristics and outcomes of thyroid cancer in Korea over the past four decades. Thyroid. 2013;23(7):797-804.

32. Oh CM, Jung KW, Won YJ, Shin A, Kong HJ, Lee JS. Age-period-cohort analysis of thyroid Cancer incidence in Korea. Cancer Res Treat. 2015;47(3): 362-9.

33. Park S, Oh CM, Cho H, Lee JY, Jung KW, Jun JK, et al. Association between screening and the thyroid cancer "epidemic" in South Korea: evidence from a nationwide study. BMJ. 2016;355:15745.

34. Ahn HS, Kim HJ, Kim KH, Lee YS, Han SJ, Kim Y, et al. Thyroid Cancer screening in South Korea increases detection of papillary cancers with no impact on other subtypes or thyroid Cancer mortality. Thyroid. 2016;26(11): 1535-40.

\section{Publisher's Note}

Springer Nature remains neutral with regard to jurisdictional claims in published maps and institutional affiliations.

Ready to submit your research? Choose BMC and benefit from:

- fast, convenient online submission

- thorough peer review by experienced researchers in your field

- rapid publication on acceptance

- support for research data, including large and complex data types

- gold Open Access which fosters wider collaboration and increased citations

- maximum visibility for your research: over $100 \mathrm{M}$ website views per year

At $\mathrm{BMC}$, research is always in progress.

Learn more biomedcentral.com/submissions 